\title{
Malaysian Higher Education Institutions: Shaping an Entrepreneurial Agenda
}

\author{
Raja Suzana Raja Kasim
}

\begin{abstract}
Despite of various challenges and obstacles to achieve the research university status, their commitment to learning and advancement of business seems to provide solutions to the emergence of entrepreneurial discipline. Researchers have their roles to play in terms of exploiting their knowledge to be more creative and innovative. The innovative researchers are those who are committed and their levels of preparedness are challenged by the time and commercializing of their innovations. This paper addresses the issues in the development of entrepreneurial discipline among higher education institutions in Malaysia and the United Kingdom (UK). Evidence indicates that in Malaysia and the UK, the Government and the higher education sector have been working together over a number of years to increase the impact of the higher education knowledge base on business and society. Despite several salient drivers of the emergence entrepreneurial discipline in higher education; many higher education institutions fail to adequately utilize its strategic knowledge resources and translate their research outputs into business innovation and social benefit. In view of this, an analysis of selected universities in Malaysia was undertaken to determine the extent to which research university status, creativity and innovative roles could impact the development of entrepreneurship in the university. This was then compared to relevant university experience in the UK. Evidence from the survey suggests that research university focus, creativity and innovative roles explain $57 \%$ of the variance in predicting the success of an entrepreneurial venture. Further, an important management implication of the study is that the entrepreneurial activity is embedded within the teaching and research and is at the core of academic identity.
\end{abstract}

Index Terms - entrepreneurship, entrepreneurial university, innovation, knowledge-based, higher education, Malaysia

\section{INTRODUCTION}

Higher Education Institutions (HEIs) have a strategic role in the dissemination, creation and application of knowledge. They appear to be known as center of knowledge as they create stock of knowledge and expertise. HEIs are equipped with relevant knowledge-generating capabilities and they also have research facilities which allow them to engage in science-based entrepreneurial activities [1]. That is why, in these recent years, universities are considered to be central to a knowledge-driven economy. Although it is said to be central to knowledge-driven economy and appears to have a world-class research base, both HEIs in Malaysia and the UK have not been very effective at translating research outputs into business innovation, competitive advantage and social benefits. This is in spite of the fact that the

Raja Suzana Raja Kasim is with Faculty of Office Management and Technology, Universiti Teknologi MARA Malaysia (e-mail: rsuzana@salam.uitm.edu.my).
Government and the higher education sector have been working together over a number of years to increase the impact of the higher education knowledge base on business and society. Embedding and fostering enterprising culture into the system and policy of HEI appears to be one of the driving factors which can help to translate the knowledge output of the university into business innovation.

A lot of effort and emphasis in fostering an enterprising and entrepreneurial culture or a corporate university within higher education has also been made among HEI in the world. According to [2], the enterprise university is about corporate-like executive higher education governance, where public policy has dramatically increased managerialism at universities. These authors had studied perception among higher education in Australia of which they agreed that academic capitalism or corporate university sound too unidimensional in terms of focusing on profitseeking. They prefer the term enterprise university because it captures both economic and academic dimensions and is, as much about generating institutional prestige as about income.

The involvement of government in encouraging this enterprising/corporate university has led to a number of initiatives being introduced at universities particularly across the UK. According to [3], the trigger for much of this was the Science Enterprise Challenge six years ago, with the formation of 13 Science Enterprise Centres (SECs) across 65 UK universities. The author further claimed that these centres would help establish links between universities and business and promote a culture of enterprise and facilitate the commercial exploitation of scientific research. Together, they have shown an impressive track record as catalysts of cultural change: 45,000 students educated in enterprise, enhanced skills of 1,800 education professionals and supported 1,000 start-ups (Enterprise - UK SEC newsletter, 2004 in [4]).

The above example had shown some evidence that entrepreneurial activities and education should, therefore, not only benefit students, but add greatly to wealth creation and national prosperity [4]. This is further supported by [5] that claimed further that in order to respond, universities need to formulate a coherent policy that will initiate a cultural change to foster corporate, enterprise and entrepreneurship.

In Malaysia, to date, there are 22 public universities, 40 private universities and university colleges, 5 branch campuses of international universities, 25 polytechnics, 39 public community colleges and 470 private colleges offering higher education opportunities. According the [6]:

"...Ministry of Higher Education is working to establish Generic Student Attributes or GSA to make 
sure all the students will enrich themselves as a complete and comprehensive student who has a numbers of added values such as communications skill, the ability to think critically and solve problem, leadership skill and team spirit and entrepreneurship skills. These efforts are designed to encourage both the academic and social development of our graduates. These GSA also should be embedded in the extra-curricular activities through clubs, sports, cultural and other non-academic activities during which students will learn how to organize events, lead others in accomplishing projects, communicate their creative thoughts and ideas to committee members, learn how to manage time, resources and finances, and at the same also acquire "people skills" and social skills such as public relations, public speaking, protocols etc. These are precious soft skills that are not taught in the formal academic curriculum, but rather would have to be acquired informally through such practical experiences. Thus, by teaching students to be not only academically and technically competent, embedding these graduate attributes in their other university activities will make students very employable either as employees in established organizations, or as independent entrepreneurs on their own. These are the kind of graduates universities must produce...".

In order to face the challenges of this new century, the Ministry of Higher Education Malaysia had made several efforts to transform graduates to become individuals with added values such as communications skill, the ability to think critically and solve problem, leadership skill and team spirit and entrepreneurship skills.

While HEIs in Malaysia are making efforts and shaping the production of graduates employable as business entrepreneurs, in the UK, many initiatives had been done among their HEIs in terms of pursuing their university toward entrepreneurial disciplines. The Higher Education Funding Council for England (HEFCE) had awarded funding to 130 higher education institutions and 123 education colleges institutions. Additionally, a range of policies supports third stream (TS) activities to enhance engagement between Higher Education Institutions (HEIs) and business, the public sector and the wider community. The country has a small number of highly innovative business sectors and large organizations that are extremely effective at accessing, absorbing and exploiting the knowledge base [7]. The Government aims to extend these innovation capabilities across a wider number of sectors and businesses to raise UK competitiveness and productivity.

The HEFCE is supporting this objective in a variety of ways. Under the experimental third stream Strategic Development Fund (SDF), HEIs have been invited to bid for funds to support experimental projects exploring activities in knowledge exchange [7]. The projects will have particular focus on increasing and deepening engagement with new sectors, SMEs and entrepreneurs on a regional level, and are intended to enable HEIs to consider the potential for adopting an organizational mission with significant emphasis on third stream activities, the so-called 'third stream as second mission.' These activities focus on technology transfer, which highlights the role of the university as generating an entrepreneur which develops the notion of industry, government and university interlinked for the purpose of innovation and entrepreneurship.

Another effort was the establishment of the University Enterprise Networks (UENs) launched on 20 November, 2008, which appears to be the first network managed by the National Council for Graduate Entrepreneurship (NCGE). The UENs aim to establish a culture of enterprise in universities by providing training, advice and encouragement to students and graduates who want to develop their business ideas or wish to become innovative employees [8]. Each network will be further supported by sponsorship from privately owned companies and Regional Development Agencies (RDAs); which in turn will give students first-hand experience of enterprising workplaces [8].

A similar kind of arrangement was also conducted in Malaysia, to encourage graduates of higher education and industry and appears to stimulate the quality of linkages between business and universities. The focus is on entrepreneurship which is at times, expressed either in the development of the quazi firm, technology transfer offices and research groups. In Universiti Teknologi MARA Malaysia (UiTM), 'Projek Tunas Mekar,' was initiated by the former Prime Minister of Malaysia, Tun Abdullah Ahmad Badawi. The main objectives of this project are twofold: to expose graduates to the world of entrepreneurship and to improve the performance of small and medium enterprises (SME) in Malaysia. In this project, the academic entrepreneur trains graduates and further equips them with new management techniques. This involves placing them with SMEs as apprentices for a period of one to two years. In this way they will learn valuable firsthand experience, which will in turn stimulate their interest to concentrate on choosing to become entrepreneurs as a career choice. Thus it seems that the definition of an entrepreneurial university is developed from an entrepreneurial academic perspective, either through developing new firms, organizations and patterns; or developing individual staff academics and graduates to be more entrepreneurial.

\section{ENTREPRENEURIAL ACTIVITIES AND EDUCATION}

In order to expand entrepreneurial education within a university, the entrepreneurial activity should not be studied as a separate activity from teaching and research, so HEIs should have a different mission to encourage these developments. In line with this agenda, the Malaysian Entrepreneurship Development Centre (MEDEC), which was also the first network managed by UiTM, emphasizes further the importance of building strong relationships between HEIs and employers. This is, of course, all the more important in a time of economic recession, where employers are looking for skills and knowledge that will see them through difficult times and provide them with new innovations for the future. To this end, in response to the economic difficulties locally and abroad, MEDEC has already provided support to UiTM students by stimulating interest among them towards embracing an enterprising 
discipline. This is done through its entrepreneurship education, where it has intrinsically invested significantly in developing UiTM graduates who are responsive to the needs of employers. Within its vision to be the HE reference center for entrepreneurship studies and development, MEDEC of UiTM appears to have succeeded.

Besides MEDEC, the Higher Education Leadership Academy (AKEPT), under the Ministry of Higher Education Malaysia (MoHE), has undertaken various studies to provide information and insight geared towards supporting the emergence of corporate or enterprising universities. The aim is to ensure continuous improvement and wider engagement for the purpose of encouraging universitygenerated income. The concept of a corporate or entrepreneurial university is in line with financial issues underpinning HEIs [9].

It is noted that many universities face difficulties in creating a solely university generated income with its core activities geared towards enterprise development $[3,4,10]$. These have included enterprise modules and courses, regional and national business planning competitions and venturefests, among others [9]. While these activities have raised enterprise awareness amongst educators, students and employers, the outcomes have been sporadic and concentrated in pockets around the country [4]. Much still remains to be done. On the other hand, academic entrepreneurship such as the creation of spin-offs commercializes technological breakthroughs [10], which may otherwise remain unexploited.

Through turbulent times, both the external and internal factors that appear to contribute to the rise of corporate/enterprising universities need to be explored. This paper will extrapolate the possible consequences of the current situation in the future, highlighting the view that entrepreneurial universities could pose a possible threat to traditional public universities in the future as they may be better placed to provide a meaningful undergraduate experience to school-leavers than is currently provided in the education sector [12].

In order to formulate and implement an effective strategy for entrepreneurship development, the University would have to tackle issues of competing institutional agendas, resource allocation and staff motivation and reward [11] in carrying out its activities. Such activities are directed towards achieving a learning culture, which will result in greater numbers of students equipped and enthused to identify, create, initiate and successfully manage personal, business, work and community issues [8]. Universities have the responsibility of teaching the people who will work, lead and innovate in future. Enterprise education should therefore, benefit not only students, but add greatly to wealth creation and national prosperity. [8] also emphasises that enterprising and entrepreneurial characteristics have something to do with a propensity for risk-taking, and are underpinned by motivation, self-belief and a sense of purpose, which ultimately translate into a certain attitude and behaviour. This entrepreneurial tendency is strengthened through a skills base that includes leadership potential, ability to work in teams and good planning, organisational and networking skills [13]. In order to nurture enterprising and entrepreneurial characteristics however, there needs to be a balance between these two approaches.

\section{RESEARCH OBJECTIVES}

The general objective of this paper is to determine to what extent variances of research university focus, researcher and roles and innovative roles could predict the development of an entrepreneurship university in Malaysian higher education. More specifically, this paper attempts to:

1) Identify the levels of research university focus, creativity and innovative roles; and

2) Examine to what extent a research university focus, the creativity and innovative roles impact university entrepreneurship activities.

\section{LITERATURE REVIEW}

\section{A. Corporate /Entrepreneurship university}

A leading study on the entrepreneurial university undertaken within the Triple Helix University-GovernmentIndustry model develops the notion of industry, government and university interlinked together for the purpose of innovation and entrepreneurship [14]. [15] embeds universities within a "national innovative capacity," highlighting the quality of linkages between business and universities. The entrepreneurial university is focused on the development of the quasi firm, with technology transfer offices and research groups. In fact [14] describes the ideal situation for the formation of the Triple Helix, with an academic with a foot in both camps: one in academe and the other in industry, and firm formation within or linked to universities. However, the participating individual is a distinct entrepreneurial academic and separate from the mainstream operations of the university.

In this study the author states that "entrepreneurial ethos" and "academic leadership" are two of four necessary pillars for the development of an entrepreneurial university. Legal control over resources and organizational capacity to transfer technology through patenting and licensing and incubation are the two remaining pillars [14]. This review of an entrepreneurial university is developed from an entrepreneurial academic perspective, either developing new firms, organizations and patents or developing staff to be more entrepreneurial. [14] emphasizes the need to expand entrepreneurial education within a university. This approach to TS development is shown to be effective and is demonstrated as the basis of developments at MIT and Stanford but does not satisfactorily address his findings that: "Many academics believe that a university best fulfils its mission by limiting itself to education and research" [14].

\section{B. Third Stream (TS)}

As demonstrated by [14], the majority of work on TS relies on a definition of TS from an academic entrepreneur perspective. The definition of TS is unclear, yet TS within an entrepreneurial framework is placed within university strategic aims, mission and vision e.g "An enterprising organisation with enterprising staff and students;" with income targets, within the strategy, defining engagement in entrepreneurial and financial terms [16]. Other forms of TS 
exist but are poorly defined, measured and rewarded. The scope of TS activities is limited, with definitions of TS falling almost exclusively within entrepreneurial and commercial/financial activities.

Thus definitions of TS are varied, as it encompasses as wide a variety of activities as there are subject areas and applications. The mission, traditions, culture and organizational structures of universities are evaluated within a "diversity with excellence model," which reviews a university"s mission through activities positioned within a teaching-research/societal-academic framework. This study of the mission of a university is again a step away from the majority of papers concentrating on outcomes such as intellectual property (IP) or income generation, stating that the "commercialization of IP is a decision about generating income rather than being about a mission" [17]. Essentially this definition excludes the majority of academics. If TS is not a peripheral activity for universities, indeed it is becoming a central theme. TS research therefore needs to include these mainstream academics.

\section{Mainstream Academic vs. Entrepreneurial Academic}

Studies on relationships between knowledge transfer and university staff attitudes, in relation to measures that aim to grow TS activity, have found entrepreneurial academics in Science/Engineering and Humanities/Social Sciences [18]. [18] found that academics with no/low external links view actions with business as a risk for academic values, believing that they will have a negative effect on department collaboration and result in a change in standards, reducing interest in teaching. The range of knowledge exchanges used by the author focused solely on research and research use, separating mainstream teaching from its links with research and TS.

The perspective within the paper is an entrepreneurial one rather than a broader TS definition developed by [17]. This does, however, support the emerging perception of academics with no/low outside links that TS is a separate activity from core activities, which supports commercial, business values and financial measures rather than mainstream academic activities and values [18]. This notion of mainstream academic identity differing from the "entrepreneurial academic" identity is supported by [19]'s study of staff entrepreneurial activity in relation to financial/incentive systems within universities undertaking technology transfer. The research found that for University Technology Transfer Offices (UTTO) staff, there was a positive relationship between financial motivators and successful entrepreneurial activities. Thus, reinforcing goal symmetry in line with general agency theory confirms that individuals will be motivated to pursue and complete entrepreneurial activity due to the motivations of formal incentive schemes, in this instance, pay [20].

However, with scientists or academic staff and their departments the relationship was found to be negative; financial motivators did not positively affect successful entrepreneurial activity. This led to discussion on academic achievement and being published as motivational drivers, not the commercial value of any research for mainstream staff, although these drivers or motivators remain untested. The study reinforces the notion that the "entrepreneurial education" are successful within third stream and operate in a manner familiar to business, i.e. incentivized with pay. The mainstream academic staff however did not fall into this category and the negative relationship between pay and engagement raises questions as to what do academics identify with, their values and how they perceive their position, organization and the nature or definition of TS within their academic area.

The reason for interest in academic entrepreneurship usually centres on the reported economic benefits arising from the commercialisation of science and technological knowledge [14. 15]. The ideas of a knowledge pump, or engine, have a resonance among policy makers attempting to characterise the dynamic role of universities in regional and national economies. The exemplars of Stanford University and Silicon Valley in the USA and Cambridge University in the UK $[14,15,18]$ are often held as the models to emulate. However, within the UK there is a perception that the entrepreneurial potential within universities needs to be more actively stimulated $[15,18]$.

The term entrepreneur is equated with small business [21] and the concept of owner management and self-employment. However this is too over simplifying the concept. The term is much broader than these concepts would suggest. Not all owner managers are entrepreneurs, not are all small businesses entrepreneurial and not all are large businesses are an enterprising. Unfortunately though, there remains no agreed definition of what constitutes an entrepreneur. Writing in 1986, Brockhaus and Howitz recognised that"....the literature appears to support the argument that there is no generic definition of an entrepreneur." [17] have suggested that"....the problem of identification of an entrepreneur has been confounded by the fact that there is still no standard, universally accepted definition of entrepreneurship. The origin of the terms which stems from the French verb, "entreprende" - to undertake. Thus entrepreneur is someone who undertakes to make things happen, and does. [22] that "Entrepreneurship is the ability to create and build something from practically nothing. It is initiating, doing, achieving, and building an enterprise or organisation, rather than just watching, analysing or describing one.

There are numerous reasons for the contemporary interest in entrepreneurship and the creation of entrepreneurs. For [21] there are essentially three main reasons, namely;

- Job creation and economic development,

- $\quad$ Strategic adjustment/realignment; and

- Deregulation and privatisation of public utilities and state owned enterprises.

Consequently, the activity of the research university focus has a strong linkage to the activity of entrepreneurial. Leading research universities in industrial-relevant fields of science are often actively involved in contract research, consultation, and other R\&D linkages with industry in order to generate additional funding for research, as well as obtaining and consolidating strategic positions within the knowledge markets and innovation networks. Several of these 'third income stream' activities are relatively easy to quantify and monitor in terms of indicators capturing financial flows, as are the outputs of entrepreneurial science in terms of patents, spin-off companies, and amounts of 
revenues and new jobs generated [23].

\section{The Research University Focus vs the Researchers creativity and innovativeness}

The association between the research university focus and entrepreneurial activities appears to be closely related. An emphasis on graduate education and research is among the most important components that make up research universities. In Malaysia, the research university focus appears to occupy a unique position, where faculty members are expected to devote a larger amount of their time to research on top of their ordinary teaching load. Hence, the faculty members' primary role now appears to be more researchers rather than teachers. Researchers are expected to publish articles and books and keep on securing more and more research grants from external sources.

The next important criteria in explaining the research university focus is the ability to produce numbers of postgraduate students, and with specialized graduate education. The graduate education and research functions are geared towards a new model focusing on student development and providing student services. The quantity of postgraduates, and the appointment of post-doctoral positions at national and international levels will be counted. On top of this, the number of PhDs graduated in a year as well as the ratio of PhDs graduated to academic staff in the field of science and technology are also taken into account. Given the variance in the characteristics of the research university focus, this paper highlights to what extent these activities impact the activities of entrepreneurship.

In explaining the role of the researchers, the features of a comprehensive undergraduate curriculum appears to function similarly and occupies a significant focus for Malaysian research universities. However, under pressure to do research, faculty members are sometimes researchers first and teachers second. The common role of researchers in the research university is to be more involved in graduate education and research. Similar to a traditional public university, all research universities offer degree programs up to the doctorate. Hence, the necessity is there for researchers to play an important role in their obligations towards academic and student development, management enhancement and human resource issues.

\section{E. Innovative roles}

This paper is based on an assumption that innovation and a corporate/enterprising university agenda are closely related to each other. Through the development of effective partnerships between universities and businesses as well as communities, a set of productive exchange of knowledge and expertise could be achieved. In the short and long-term, these partnerships may deliver economic and social benefits, particularly in innovation, enhanced growth, efficiency and cohesion and the development of employment skills.

According to [24], relations with industry have become further complicated as companies see the university as a potential competitor through its role in the creation of new firms. He further argued that although some academics and industrialists wish the university to return to its traditional role of training students and publishing research findings, many states and local governments fund centres and programs to encourage academic institutions to generate new economic activity from the campus. [24] also claim that indeed, venture capitalists advise prospective academic founders of companies that the best way to launch their firm is to remain on campus and work with students to develop the early stages of their technology and as further discussed below:

"Although many academics would prefer to return to an era when federal support was sufficient to meet the needs of their research enterprise, few see this as a realistic possibility. The conflicts are no longer about whether the university should pursue knowledge for profit, but over the shape that organizational innovations to accommodate industry connections will take." [24].

In shaping the organizational innovation, "innovation" is a continuum that spans from the incremental improvements new to a firm to a radical invention new to a global market [25]. [5, 24, 25, 26, 27] argue that all firms have their own approach and method for developing new or innovative ideas that create value. For many technology companies, the innovation process is a research and development activity; service companies, on the other hand, often have a creativity department; still others rely on their employees in the field to produce innovative ideas.

Every year hundreds of thousands of people leave university with undergraduate degree qualifications. Their knowledge, skills and qualities are vital building blocks of a high value-added economy. As well as specialist knowledge, graduates bring with them distinctive skills in critical thinking, the ability to manage complex information, communication and team working. But beyond this, graduates have the ability to change the jobs that they do and to solve the problems that organizations did not even know existed. Businesses employing graduates are more likely to innovate than those who do not; that are why employers pay more to graduates than to non-graduates. These graduates become important organizational knowledge. Therefore, if organizational knowledge is important, for what purpose should organizations develop and share knowledge? According to [28], innovation, or bringing something new into being, is one of the most vital uses of shared organizational knowledge. They further argue that innovation takes place in organizations in the form of new products, new processes to use to create products, and new administrative structures and routines to use to help the organizations operate efficiently and effectively.

In the context of HEIs, the emergence of a corporate/enterprise which links to innovation activities appears to be a source of competitive advantage and serves as a path to higher levels of financial or non-financial performance. Further in the view of HEIs, a corporate/enterprising activity is an important path that the university can take to make it possible for the academic members and graduates to engage in entrepreneurial behavior, using knowledge as a foundation for continuous and successful innovations as they do so [18]. Hence, it is vital to measure the direct impact of innovation on corporate/enterprising activities through its achievement of number of patents granted at national and international levels, products licensed for commercialization, technology- 
knowhow licenses and IPR/copyrights (including original writings).

Ultimately, in addressing the question of whether and how these HEIs can cope with the transformation and change of paradigm towards corporate and enterprising university, this research aims to take a close look to what extent do research university focus, creativity and an innovative roles impact corporate and enterprising university. In the local perspective, there has been little research on the extent research university focus, creativity and innovative roles impact its entrepreneurial activities. Hence, this paper seeks to identify to what extent research university focus, creativity and innovative roles impact the entrepreneurial activities among selected universities in Malaysia. In meeting these objectives, a theoretical framework which also serves as a conceptual framework of these relationships has been developed as below:

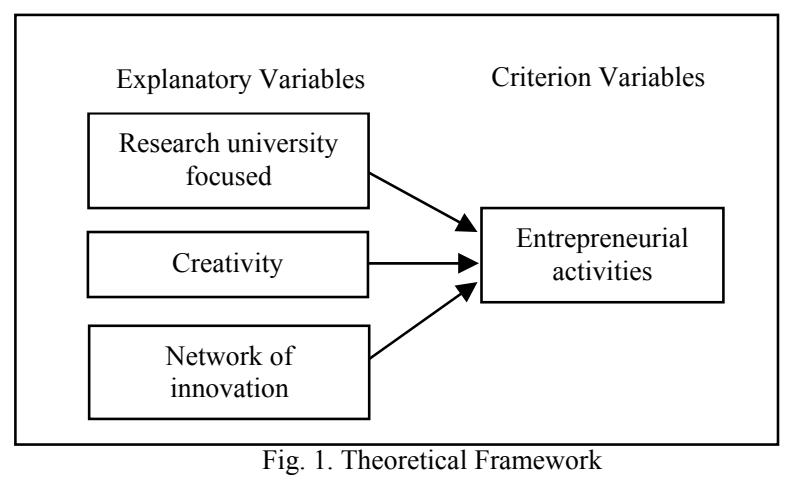

\section{RESEARCH DESIGN}

Next, a correlational research design developed. This is followed by a quantitative approach using a survey technique. A set of questionnaire was developed which comprises four main sections. The first section consists of two parts; namely, entrepreneurial activities (adapted from [29]), and enterprising education developed by the researchers integrating various perspectives from the field of strategic management and entrepreneurship education. The second, third and fourth sections on research university focus, creativity and innovative roles respectively were developed by the researchers by modifying and extending the constructs found in the related literature from higher educational studies concerning these variables. The researchers needed to integrate the above perspectives so as to achieve some relevancy and develop a more appropriate content of the paper. Finally, the fifth section on the profile of the respondents was also developed by the researchers, validated and found to be reliable and valid. In this paper, the researchers developed a ten-point scale with values ranging from " $1=$ don't agree at all/don't achieve at all" to " $10=$ completely agree/completely achieve." In this respect, the proposed scale constitutes an improvement over the approach by [29].

By the close of the survey at the end of March, 2010, a total of 382 responses were received, of which 362 were useable. The above ended the survey administration and data collection process. The gross response rate was $63 \%$. Hence, after considering the 20 unusable responses, a total of 362 responses were deemed usable and the effective response rate was $60 \%$. The instrument was categorized into four sections and the alpha coefficient was calculated for these sections and for the questionnaire in its entirety. The level of significance for items was established at .05. The alpha score obtained for all four sections were above .80 and this was generally accepted for field research [30]. Additionally, according to [31] the value of alpha level of more than 0.6 shows the research instrument is reliable for the purpose of the paper. The data therefore suggested that the questionnaire was a reliable instrument to consistently measure the variables in the paper.

\section{VI.. DATA ANALYSIS AND RESUltS}

In the following sections, the demographic profile of the respondents is discussed. Basically, the respondents for the research consisted of 362 respondents, 74 percent female and 26 percent male. Therefore, it could be said that the male respondents were one third of the total respondents. Of these 273 respondents, $53 \%$ have some working experience in business/industry, while another $47 \%$ claimed that they have no experience.

Ethnic

From all the 362 complete answered questionnaire collected, it was found that the majority of the respondents were Malays academic researchers. The percentage of Malays respondents was 95.6 percent, 1.5 percent were Chinese respondents, 1.8 percent were Indian respondents and and 1.1 percent were from other races.

The composition of ethnic groups in the sample between Malays and non Malays is in line with the overall ratio of ethnics in professional and management group scheme; the ratio of 4 for Malays to 1 non- Malay.

Age Group

In terms of age distribution 40.3 percent of the respondents were between 30 to 44 years old, another 33.3 percent were under 30 years and 26.4 percent were between the ages of 45 to 54 years. The wide age range indicates a diverse sample.

Educational Level

From the data on educational level, 70.3 percent of the respondents were masters' degree holders, 12.5 percent and 12.8 percent of the respondents were bachelor's degree holders and with $\mathrm{PhD}$ qualifications respectively, another 2.9 percent of the respondents with baccalaureate qualifications, and only 1.5 percent of the respondents had obtained less than baccalaureate qualifications. This has also indicated a diverse sample.

Job Category

For job category or ranking of the respondents, 73.6 percent of the respondents were academic researchers, 9.2 percent were coordinators/assistant coordinators and head of programs/departments respectively, and 3.7 percent were those of head of center/institute/center for excellence and deputy deans/deputy directors respectively. Some 0.7 percent were from other job category.

Working Experience

From the data collected, 30.8 percent of the respondents had working experience between 4 to 5 years, 19.8 percent had between 6 to 10 years working experience, 19 percent had between 11 to 15 years working experience, 16.1 
percent had between 2 to 3 years working experience, 7.3 percent had working experience between 16 to 20 years, and 7 percent of the respondents had 1 year of working experience. The service duration also indicates some diversity. The wide range of working experience also indicates a diverse sample.

\section{A. Research Question 1}

What are the levels of research university focus, creativity and innovative roles as identified by academia of HEIs in Malaysia?

The findings indicate that the mean ratings for research university focus, the role of the researcher and innovative roles in descending order of high to low were; the role of the researcher $(M=7.69, S D=1.131)$, innovative roles $(M=$ $6.99, S D=1.146)$ and research university focus $(M=6.75$, $S D=1.655)$. For the overall sample, the variable means ranged from 6.75 to 7.69 .

\section{B. Research Question 2}

To what extent do research universities focus, the creativity and innovative roles impact university entrepreneurship activities?

To explore research objective 2 in determining to what extent research university focus, researcher role and innovative roles impact corporate/enterprising university activity, a multiple linear regression was used to analyze the data. A number of assumptions were checked before running the output to ensure no violation of the assumption of multicollinearity, normality, linearity, and homoscedasticity was done.

The following hypothesis was made:

$\mathrm{H}_{1}$ There is a positive, linear, and significant relationship between variance impacting corporatelenterprising university activities and the factors: (a) research university focus, (b) the role of the researcher and, (c) network of innovation.

In order to determine how much variance impacts corporate/enterprising university activity can be explained by scores on research university focus, the role of the researcher and innovative roles; a three predictor multiple linear regression model was proposed. The three predictor variables are research university focus, $\left(\mathrm{X}_{1}\right)$, the role of the researcher $\left(\mathrm{X}_{2}\right)$, and innovative roles $\left(\mathrm{X}_{3}\right)$. Based on this method, all the three predictor variables were found to be of significance in explaining corporate/enterprising university activity. As depicted in the coefficients table (see Table 1), the estimated model is as below:

$$
Y(\text { EntUni })=2.995+.346\left(X_{1}\right)+.374\left(X_{2}\right)+-.102\left(X_{3}\right)+e
$$
where:

$Y=$ entrepreneurial activities

$b_{0}=$ Constant (Intercept)

$b_{1-3}=$ Estimates (Regression coefficients)

$X_{1}=$ research university focus

$X_{2}=$ the role of the researcher, and

$X_{3}=$ innovative roles

$e=$ Error.

The R-squared of 0.571 implies that these predictor variables explain about $57.1 \%$ of the variance/variation in corporate/enterprising university activity. This is quite a good result. The ANOVA table revealed that the F-statistics (158.56) and the corresponding p-value is highly significant
(0.0001) or lower than the alpha value of 0.05 . This indicates that the slope of the estimated linear regression model line is not equal to zero confirming that there is a linear relationship between corporate/enterprising university activity and these predictor variables.

\begin{tabular}{|c|c|c|c|c|c|}
\hline $\begin{array}{l}\text { Entrepreneurial } \\
\text { University } \\
\text { dimension }\end{array}$ & \begin{tabular}{c}
\multicolumn{1}{c}{ B } \\
(Unstdardized \\
Coefficients) \\
\end{tabular} & $\begin{array}{l}\text { Std. } \\
\text { Error }\end{array}$ & \begin{tabular}{|c|} 
Beta \\
(Standardized \\
Coefficients) \\
\end{tabular} & $\mathrm{t}$ & $p$-value \\
\hline Constant & 2.995 & .243 & & 12.338 & 0.000 \\
\hline $\begin{array}{r}\text { Research } \\
\text { University } \\
\text { focused }\left(\mathrm{X}_{1}\right) \\
\end{array}$ & .346 & .044 & .567 & 7.949 & 0.000 \\
\hline Creativity $\left(\mathrm{X}_{2}\right)$ & .374 & .043 & .419 & 8.641 & 0.000 \\
\hline $\begin{array}{r}\text { Network of } \\
\text { innovation }\left(\mathrm{X}_{3}\right)\end{array}$ & -.102 & .032 & -.205 & -3.185 & 0.000 \\
\hline
\end{tabular}

\section{IMPLICATIONS TO THE THEORY AND BODY OF KNOWLEDGE}

The following discussion outlines the contribution this paper can make in two interdisciplinary areas of entrepreneurship and higher education.

\section{A. Implications for policy and practice}

HEIs can use this paper to better understand the best set of conducting activities and strategic goals that a university should employ and ways to apply them. The top management of HEIs, the MoHE, as well as AKEPT as policy-makers, should continuously emphasize improvement in the governance of HEIs. The management of the HEIs has an early exposure as intellectual capital represents significant value to their bottom line. Thus, this paper will contribute to this body of knowledge, i.e. the HEIs as the main platform of the country's competitiveness with good academic and entrepreneurial skills with behavior and leadership governance in higher educational studies.

\section{B. Curriculum development}

This paper is also relevant to academicians as the basis for leadership challenges issues to venture into enterprising which start in the higher educational sector. The findings can help academicians to be more aware on this matter and give more emphasis on entrepreneurship leadership management and encourage students to improve personal competencies and skills in entrepreneurship. Since education is the primary function of any university, the enterprising/entrepreneurial issues should be strategic and have a clear tie-in to the individual HEIs mission. Its activities, may range from classroom learning to distance learning, succession planning, knowledge management, strategic hiring as well as other possible activities.

\section{Limitations and Future Studies}

Prior to discussing the conclusions of this paper, it is necessary to recognize some of its limitations, thus the researchers recommend an option based on these limitations. Among the limitations concerned is the need to use longitudinal data for more stability. Besides, generalization to different levels of management and organizations should be done cautiously and subject to further study. Other than that, future research should examine alternative measures of organizational performance, knowledge management and learning management systems through other theories or 
perspectives in the discipline. Another limitation observed is the underlying influential mechanisms or controlling factors that would affect the relationship of the variables. Last but not least, the instrument could be further enhanced to include other techniques such as observations and interviews for better quality output in the future.

\section{CONCLUSION}

HEIs are shaped by, and themselves shape, the country's economy and society. Through world-class teaching, research, and increasingly closer interaction with businesses and communities, they are helping to create the conditions which will lead the country out of recession to full recovery. Higher education is an engine of economic, social and cultural development in local communities and across the country as a whole.

The results of this paper add to our understanding of the impact of research university focus, creativity and innovative roles on entrepreneurial activities and their significant implications towards the performance of academic leaders and HEIs. Nevertheless, working towards the knowledge and innovation era, HEIs should fully venture into the enterprise agenda. The results not only have the potential to contribute theoretically to both management strategy and entrepreneurship literature but also to higher educational studies. While previous studies claimed strategies can contribute to the performance of the organization, this paper indicates that HEIs emphasize research university focus, the creativity and network of innovation.

\section{ACKNOWLEDGMENT}

The researcher thanks the Higher Education Leadership Academy, Ministry of Higher Education Malaysia for the funding and dedicated support towards this project. The researcher also thanks the management and staff of the Research Management Institute, Universiti Teknologi MARA Malaysia in providing constant assistance towards the accomplishment of this research project.

\section{REFERENCES}

[1] F.T. Rothaermel, S.D. Agung and L. Jiang, University entrepreneurship: A taxonomy of the literature. Industrial and Corporate Change, Oxford University Press. 2007, 16: (4),691-791.

[2] S. Marginson and M, Considine, The enterprise university. Cambridge: Cambridge University Press. 2000

[3] R. D. Handscombe, "The promotion of an entrepreneurial culture in universities-capturing change in the cultural web," Industry and Higher Education, 17(3), 2003, 219-22.

[4] S. Kothari, and R. D. Handscombe, "Sweep or seep? structure, culture, enterprise and Universities," Management Decision. 2007, 45(1), 43-61.

[5] D. S. Siegel, M. Wright, and A.Lockett, "The rise of entrepreneurial activity at universities: organizational and societal implications," Industrial and Corporate Change, 2007, 16(4), 489-504.

[6] Mohamed Khaled Nordin, (2010). Awards Day Speech Universiti USCI. Available: http://jpt.mohe.gov.my/

[7] Higher Education Funding Council for England (HEFCE).: Experimental third stream strategic development fund projects. Quotec Ltd and University of Sussex, 3, 2007.

[8] National Council for Graduate Entrepreneurship (NCGE).: New Networks launched to boost university entrepreneurship. http://ncge.wordpress.com.
[9] B. R. Clark, "Sustaining change in universities: continuities in case studies and concepts," Tertiary Education and Management, 2003, 9, 99-116.

[10] E. Burg, A. G. Romme, V. Gilsing, and I. Reymen, "Creating university spin-offs: a science-based design perspective," J. Product Innovation Management. 2008, 25(2), 114.

[11] H. Kroll, and I. Liefner, "Spin-off enterprises as a means of technology commercialization in a transforming economy-evidence from three universities in China," Technovation. 2008, 28(5), 298.

[12] E. Blass, "The rise and rise of the corporate university," J. European Industrial Training. 2005, 29 (1), 58-74.

[13] W. A. Lucas, and S. Y. Cooper, "Enhancing self-efficacy to enable entrepreneurship: the case of CMI's connections," paper presented at 12th Annual International High Technology Small Firms Conference, University of Twente, Enschede, The Netherlands, 2004.

[14] H. Etzkowitz, "The triple helix university-industry-government innovation in action," New York: Routledge, 2008.

[15] J. L. Furman, "The determinants of national innovative capacity," Research Policy, 2002, 31 (6),899-933.

[16] MMU.:Vision of the future. online http://www.mmu.ac.uk/about/vision.

[17] M. Wedgwood, "Mainstreaming the third stream. In: I.MCNAY,ed.,Beyond Mass Higher Education, New York: Open University Press, 2006, 134-157.

[18] A. Martinelli, "Becoming an entrepreneurial university? a case study of knowledge exchange relationships and faculty attitudes in a medium sized research-oriented university," J.Technology Transfer, 2008, 33 (3), 259-283.

[19] G.Markman, "Entrepreneurship from the Ivory Tower: do incentive systems matter?" J.Technology Transfer, 2004, 29,353-364.

[20] K. M. Eisenhardt, "Agency theory- an assessment and review," Academy of Management Review, 14 (1), 1989, 57-74.

[21] A. Gibb, Entrepreneurship and small business management: can we afford to neglect them in the twenty-first century business school. Britisth Journal of Management, 1996, 7(4), 309-21.

[22] J.A. Timmons, The Entrepreneurial Mind, Brick House Publishing, Andover, MA, 1989.

[23] J. Molas_Gallart, Measuring Third Stream Activities, 2002.

[24] H, Etzkowitz, The norms of entrepreneurial science: Cognitive effects of the new university-industry linkages. Research Policy, 1998, 27(8), 823-833.

[25] J. Oksanen and N. Rilla, "Innovation and entrepreneurship: new innovations as source for competitiveness in Finnish SMEs," International J. Entrepreneurship. 13, 35-48, 2009.

[26] K.Tajeddini and S. L. Mueller, "Enterpreneurial characteristics in Switzerland and the UK: a comparative study of technoentrepreneurs," J. International Entrepreneurship, 2009, 7, 1-25,

[27] F. T. Rothaemerl, "University entrepreneurship: a taxonomy of the literature," Industrial and Corporate Change, 2007, 16 (4),691-791.

[28] R. D. Ireland, D . F. Kuratko and H. M. Morris, "A health audit for corporate entrepreneurship innovation at all levels: part 1," $J$. Business Strategy. 27 (1), 10-17, 2006.

[29] D. F. Kuratko, R. V. Montagno and J.S. Hornsby, Strategic Management Journal, Vol. 11, 1990, pp. 49-58.

[30] U. Sekaran, Research methods for business: a skill building approach $\left(4^{\text {th }}\right.$ ed.). India: John Willey and Son, 2004.

[31] J. C. Nunally, Psychometric Theory. New York: McGraw-Hill, 1978.

[32] R, J. W. Tijssen, University and industrially relevant science: towards measurement models and indicators of entrepreneurial orientation, 2007.

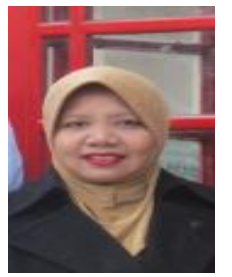

Raja Suzana Raja Kasim obtained her PhD degree in Management/Knowledge Management from Universiti Putra Malaysia and her Master in Information Management from UiTM Malaysia. She was a former Head of unit of research, commercialization and development and the Deputy Dean (Student Affairs \& Alumni), Faculty of Office Management and Technology, Universiti Teknologi MARA, Malaysia. Her research covers business and management fields, leadership, IT behavior, organizational behaviour, knowledge management practices, issues and challenges, strategies and change management. 